\title{
O Worst of do Teatro Praga
}

\section{CHRISTINE ZURBACH}

Título: Worst of. Criação: Teatro Praga. Textos: Gil Vicente, Correia Garção, Almeida Garrett, Francisco Gomes de Amorim, Júlio Dantas, Alfredo Cortês, André Brun, Luís de Sttau Monteiro, Bernardo Santareno, José Maria Vieira Mendes. Interpretação: Cláudia Jardim, Diogo Bento, Márcia Breia, Patrícia da Silva, Pedro Penim, Rogério Samora, São José Correia, Vítor Silva Costa. Cenografia: Joana Sousa. Figurinos: Joana Barrios. Desenho de luzes: Daniel Worm d'Assumpção. Desenho de som: Miguel Lucas Mendes. Produção: Teatro Praga. Co-produção: Teatro Nacional D. Maria II, Teatro Municipal do Porto. Local e data de estreia: TNDMII, Lisboa, 1 de Novembro de 2018.

\section{[...] encontrar no anacronismo, na falha, no erro, ou numa ideia de teatro tão específica e tão relativa a determinados contextos e conquistas históricas mas enclausurando-se numa ideia totalista da arte, encontrar nisso também virtudes.}

ANDRÉ E. TEODÓSIO

Entrar na peça Worst of do Teatro Praga pela leitura da «Conversa com o Teatro Praga», publicada no formato de uma entrevista com Maria João Guardão, no programa do espectáculo da companhia (2018: 6-10), torna certamente mais explícitos e nítidos os contornos de uma proposta teatral invulgar e, na verdade, algo surpreendente no panorama actual da oferta teatral, tanto pelo seu tema como pelo modo como o desenvolve. Com efeito, a particularidade desta última criação do grupo, apresentada no Teatro Nacional D. Maria II a convite do seu director artístico, Tiago Rodrigues, consiste no facto de afirmar e ao mesmo tempo questionar, «na casa da dramaturgia e do teatro português, fundada pelo Almeida Garrett» (ibidem), uma imagem consagrada de desvalorização ou até de negação da existência histórica de uma dramaturgia portuguesa.

É de todos conhecida a afirmação de Eça de Queirós acerca dos Portugueses e da sua falta de tête dramatique, opinião de resto paradoxal numa época de afirmação da arte teatral na Europa e em Portugal, em que Garrett implementa, por incumbência da coroa, o seu programa de criação de um teatro nacional (Ferreira, 2014). 


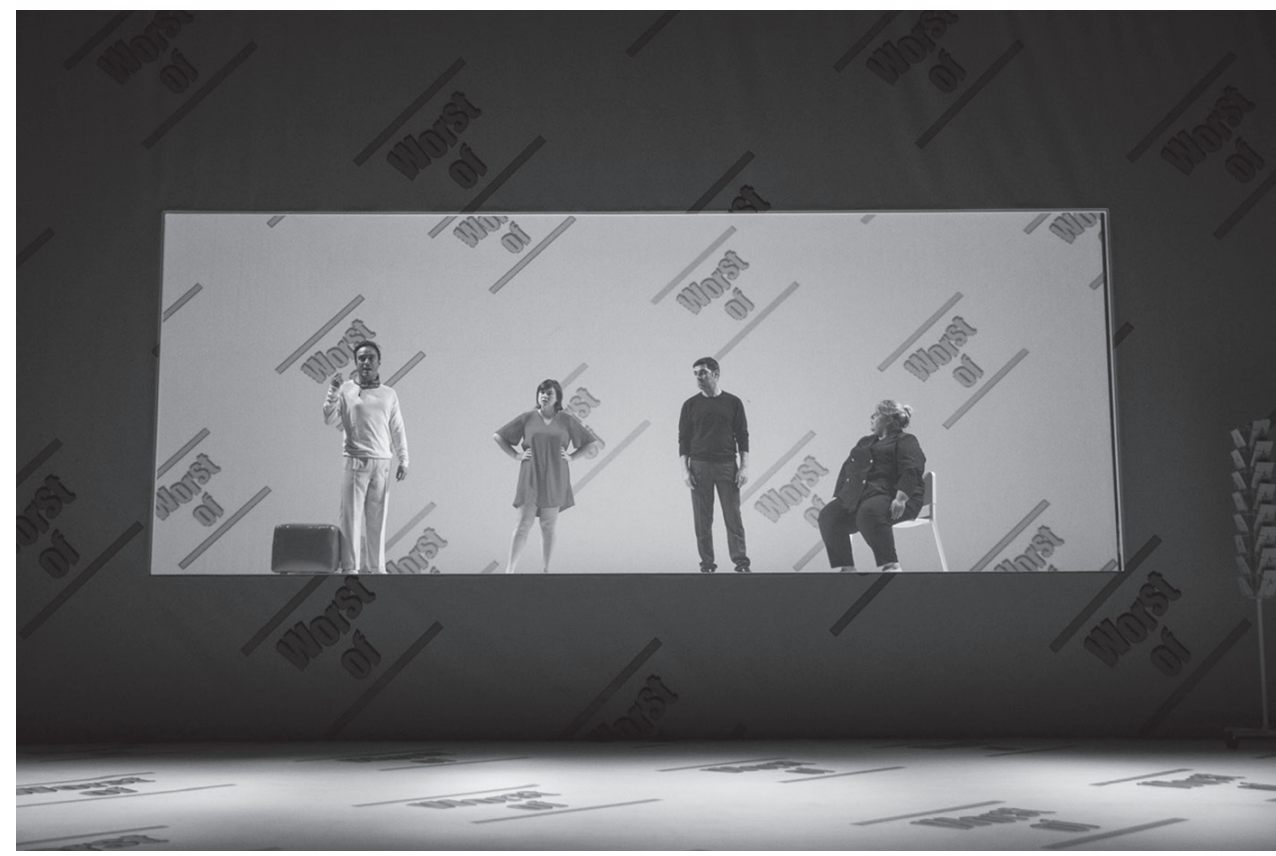

WORST OF, CRIAÇÃO DE TEATRO PRAGA, TEATRO PRAGA, TEATRO NACIONAL D. MARIA II

E TEATRO MUNICIPAL DO PORTO - RIVOLI, 2018 (PEDRO PENIM, PATRÍCIA DA SILVA, DIOGO BENTO,

CLÁUDIA JARDIM), [F] FILIPE FERREIRA

Como falar, em 2018, duma herança conotada como teatro mau, tendencialmente ignorada ou esquecida pela maioria dos encenadores e actores, salvo raras excepções, como Vicente e Garrett, únicos a terem escapado à ilustre condenação sucessivamente retomada ao longo da História? A começar pelo seu título, pode um espectáculo como Worst of contrariar um discurso apenas interessado em narrar um desastre? Este é o desafio de Worst of, concebido como uma visita de estudo ou uma viagem museológica pela História do teatro português; um desafio que o Teatro Praga fez a si mesmo, seguindo o seu gosto em «conseguir lidar com as coisas negativas» (idem:7), e que implica o público a quem «[dão] essa possibilidade de fazer a sua visita de estudo, pensada por [eles]» (idem: 8). Coerente com o discurso crítico sobre o teatro que sustenta o seu programa artístico e o identifica desde a fundação do grupo, o Teatro Praga decidiu «[entrar] num tipo de negatividade que é inerente à ideia daquilo que é o teatro português» (2018: 8) - o que nos diálogos surge repetidamente com a palavra ubuesca «merda». Contrariando a visão dessas obras que as histórias do teatro se esforçaram por canonizar, reconhecendo-lhes uma condição de clássicos providos de uma qualidade 


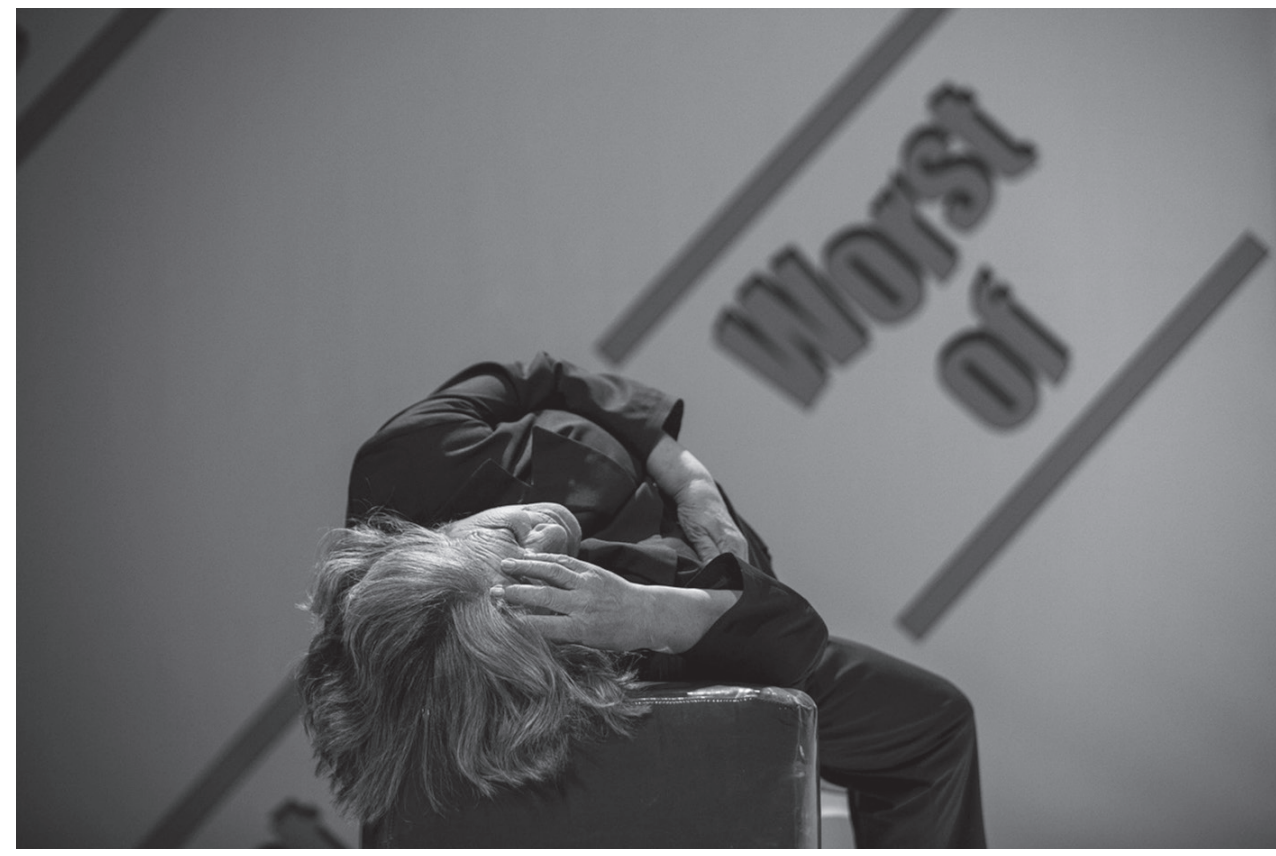

WORST OF, CRIAÇÃO DE TEATRO PRAGA, TEATRO PRAGA, TEATRO NACIONAL D. MARIA II E TEATRO MUNICIPAL DO PORTO - RIVOLI, 2018 (MÁRCIA BREIA), [F] FILIPE FERREIRA

intrínseca (ibidem), a dramaturgia do espectáculo pretende levar o espectador a questionar-se sobre a sua própria percepção da dramaturgia portuguesa. Num gesto auto-reflexivo que recorre à fórmula do teatro dentro do teatro, mesclando realidade e ilusão, o espectáculo integra um último quadro escrito pelo dramaturgo da companhia, José Maria Vieira Mendes, mostrando assim que o Teatro Praga também se inclui neste Worst of e se expõe à crítica negativa do público, num «gesto que diz "isto somos nós, também"» (idem: 9).

O próprio teatro interrogando-se sobre si mesmo, aquele que vem do passado ou aquele que se faz hoje, eis a matéria discutida criticamente num «espectáculo celebratório, mas anticelebratório, que pensasse sobre a dramaturgia portuguesa» (2018: 6). Neste Worst of existe um ponto de partida, o da evidência da indelével marca de fracasso histórico dessa herança, de Gil Vicente a Bernardo Santareno, pelo menos se nos fiarmos no discurso que sobre ela se cristalizou, o dos antagonistas (ibidem), que a proposta dramatúrgica do espectáculo teve em conta. Mas, se, para Pedro Penim, «esta evidência pode dar em lamento ou então em celebração, [o Teatro Praga escolheu] celebrar essa falta, essa inexistência» (ibidem). O objectivo será, portanto, encontrar virtudes nos defeitos de uma 
dramaturgia que, segundo os autores do espectáculo, foi excessivamente dominada por pressupostos (ou preconceitos) artísticos que a prejudicaram, em que a comparação com outros modelos ou outros países apenas tornava ainda mais aparente uma ideia de crise sem remédio.

A eficácia deste exercício de reflexão crítica é garantida pelo enquadramento visual e espacial que o espectador descobre quando entra na sala. A cenografia remete-o para um modelo expositivo simples, criado pela cenógrafa Joana de Sousa, que desdobra e multiplica a recepção das imagens, das palavras e das acções em cena.

Para dar espaço às críticas que recorrentemente condenam a dramaturgia portuguesa, tida paradoxalmente como falha de qualidade dramática, a encenação apresenta ao espectador um duplo dispositivo cenográfico (espacial e discursivo), que se situa em dois planos, destinados cada um a acolher uma área de jogo para os actores: o palco propriamente dito da Sala Garrett, onde actua um grupo de quatro actores-personagens no papel de actores portugueses da actualidade: Márcia Breia, São José Correia, Rogério Samora e Vítor Silva Costa, que são apresentados na sinopse do espectáculo como «um best of de actores nacionais» (TNDMII, 2018: 20), posição que assumem na ficção como personagens de actores. É desse lugar, mais próprio de uma sala de exposição ou de um museu, apenas mobilado por uma bancada azul, um mostruário de postais ilustrados e um extintor, que assistem ao desfile das cenas interpretadas num segundo espaço, sobrelevado, montado a meio do palco. É o lugar de exibição de uma sequência de dez dioramas - excelente solução para realçar o carácter historicamente datado dessas cenas, algumas verdadeiramente antológicas no sentido em que são aquelas que a História quis reter. Aí, Cláudia Jardim, Diogo Bento, Patrícia da Silva e Pedro Penim, actores da companhia do Teatro Praga, propõem ao espectador um confronto com o fracasso, o que a (nossa) memória do teatro insistentemente criticou e continua a criticar. De Almeida Garrett a Gil Vicente, passando sem preocupação cronológica, sucessivamente, por Luís Sttau Monteiro, Francisco Gomes de Amorim, Alfredo Cortez, Bernardo Santareno, Correia Garção, André Brun e Júlio Dantas, esse teatro é mostrado no formato do «teatro dentro do teatro» aos quatro espectadores privilegiados que assistem enquanto actores, e potenciais intérpretes, a esta colecção de cenas e personagens famosas da dramaturgia nacional, como o Romeiro e a Madalena do Frei Luiz de Sousa, o trio de cardeais da Ceia de Júlio Dantas, a maluquinha de Arroios de André Brun, o vaqueiro de Gil Vicente, entre outros. 


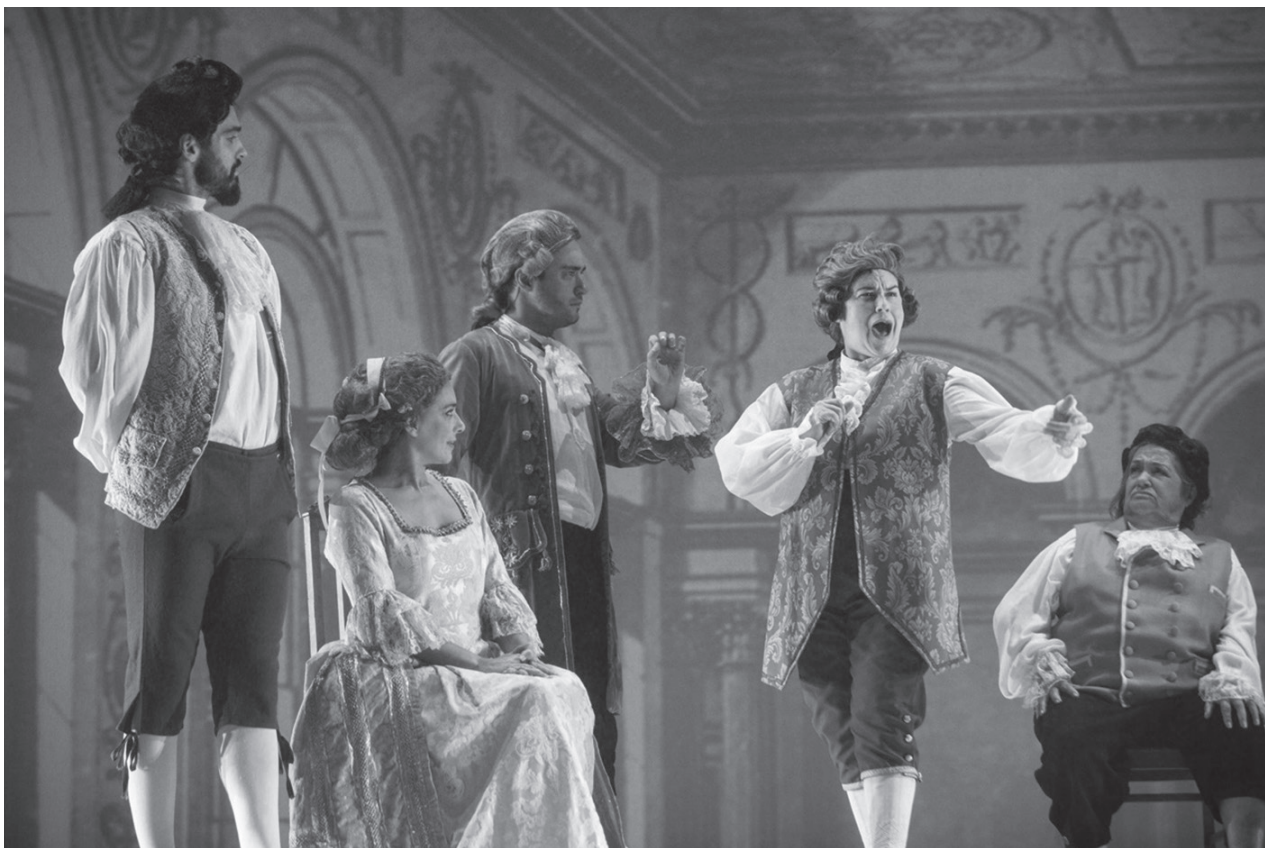

WORST OF, CRIAÇÃO DE TEATRO PRAGA, TEATRO PRAGA, TEATRO NACIONAL D. MARIA II E TEATRO MUNICIPAL DO PORTO - RIVOLI, 2018 (VÍTOR SILVA COSTA, SÃO JOSÉ CORREIA, PEDRO PENIM, PATRÍCIA DA SILVA E MÁRCIA BREIA), [F] FILIPE FERREIRA

Em diálogos breves, no fim da apresentação de cada fragmento, esses espectadores dentro do teatro comentam com desalento as cenas, numa linguagem desabrida, sem requinte nem censura. Dos quatro, três são «pessoas que já conhecem a profissão e a área de ginjeira» (2018: 9).

Para agir sobre o espectador, é visível a eficácia do dispositivo cénico, em que a encenação constrói uma relação de continuidade e proximidade com a plateia, bem aproveitada aliás, com um dinamismo vivo, pelo jogo dos actores, com maior ou menor cumplicidade, conforme as diversas reacções da sala. Esse espaço e a cenografia que o delineia materializam um dos objectivos da dramaturgia do espectáculo, que pretende interpelar o espectador e integrá-lo num questionamento sobre a dramaturgia portuguesa, que o Teatro Praga decidiu tirar da gaveta da Literatura e trazer para a cena. Devolvendo-lhe a sua condição de teatro «ao vivo», exposto às cenas impiedosas do grupo do best of de actores.

No conjunto, ressalta o contraste entre os dois tipos de cenas e de actuação que marcam o espectáculo, a tal ponto que se poderia falar de uma peça contranatura para os actores do Teatro Praga. A encenação revela um trabalho rigoroso na caracterização estética e histórica dessas 
cenas em que o som, a luz e os figurinos (re)criam os códigos desses clássicos do teatro português. Worst of requer uma "espécie de seriedade» (idem: 7) que passa pelo peso dado à palavra, ao texto e ao gesto que, nas cenas dos dioramas, pertencem a dramaturgias alheias às escolhas da prática artística do teatro Praga, sem o distanciamento irónico que a caracteriza, como marca própria. Pelo contrário, a crítica por vezes violenta e desabrida fica remetida para os quatro actores-personagens que os observam.

Três são unânimes em expressar uma percepção profundamente negativa que esses autores e textos lhes inspiram, mas o quarto representa uma voz dissonante. É a da personagem de Vítor: ainda no início de carreira, não participa nas lamúrias acerca dessa herança reiteradamente chamada «merda», com tonalidades de ódio ou desprezo, discurso que José Maria Vieira Mendes também considera improdutivo. De acordo com o dramaturgo, esse espectáculo «não é só isto [...], há mais para além disto, que é só o primeiro embate» (ibidem); contém uma ideia de teatro, mas que passa pelos antagonismos, e não pela celebração. O espectáculo escreve-se nessa forma desafiadora de revisitar os textos consagrados, sem preocupação em respeitar tradições (como é prática habitual do Teatro Praga), dando prova da sua vitalidade, que seria a única possibilidade para resgatar essa dramaturgia.

Se o espectáculo é muito claro neste propósito, resta-nos uma interrogação: será que o espectador consegue encontrar o seu lugar no tipo de relação e cumplicidade que pressupõe um objecto dessa natureza? Dividir a plateia não é novidade, como sabemos. Aqui, o público, com maior ou menor grau de familiaridade com os seus clássicos da literatura portuguesa, pode escolher entre a adesão à rejeição reiterada e a valorização intencional do que caracteriza a dramaturgia desses excertos, assumida nos dioramas com excelente encenação e interpretação (um segundo elenco de best of...), não deixando, afinal, de também dar espaço à celebração...

\section{REFERÊNCIAS BIBLIOGRÁFICAS}

FERREIRA, José Alberto (2014), «O caso do teatro inexistente, ou do teatro como imagem de nós», Limite, n. ${ }^{\circ} 8$, pp. 93-126.

GUARDÃo, Maria João e Teatro Praga (2018), «Damos o protagonismo a uma outra ideia de história, a dos antagonistas e da merda. Conversa com Teatro Praga», in Programa do espectáculo Worst of, Lisboa, Teatro Nacional D. Maria II, pp. 6-10.

Teatro Nacional D. Maria II (2018), Há lugar para todos. Set.-Dez.2018, Lisboa, Teatro Nacional D. Maria II. 